\title{
Mouse Rectum Carcinoma
}

National Cancer Institute

\section{Source}

National Cancer Institute. Mouse Rectum Carcinoma. NCI Thesaurus. Code C134779.

Carcinoma that occurs in the rectum of a mouse. 